\title{
USING THE ROFSET FRAMEWORK IN TRACKING, MEASURING AND ANALYSING STUDENT PARTICIPATION AND ENGAGEMENT IN CLASS
}

\author{
Izharul Haq ${ }^{1}$, Rubina $\mathrm{Haq}^{2}$, Masood Ahmed ${ }^{3 *}$ \\ ${ }^{1}$ Prof. Dr., Prince Mohammad Bin Fahd University, Saudi Arabia, ihaq@pmu.edu.sa \\ ${ }^{2}$ Mrs. International Islamic University, Pakistan, rubinahaq54@gmail.com \\ ${ }^{3}$ Assist. Prof. Mr., SZABIST, Karachi, Pakistan, masood@szabist.edu.pk \\ ${ }^{*}$ Corresponding Author
}

\begin{abstract}
Student participation and engagement during a class is considered to be one of the main factors that determine the effectiveness of teaching and student learning. It has been found that these are the best two parameters to assess students' performance in the class. A certain percentage of marks are allocated for class participation. However, the challenge is how to keep track of the quantity (number of times each student participates) and quality (the level of engagement with the topic on hand) for every student. These are not simple and straightforward tasks to achieve by the instructor during teaching. Hence, no feedback can be provided to students about performance on the basis of their class participation and engagement.

There are few standalone applications available in the market but they do not provide real-time student feedback. Furthermore, these applications are usually time consuming to setup and use effectively in class. For this reason, it is found that most teachers simply keep some sort of mental memory or manually take notes regarding each student's class participation. These methods are ineffective, inaccurate and add extra burden on the instructors.

In this paper, we evaluate the ROFSET framework that provides a unique method for tracking, measuring, and analyzing student participation in every class and for every student automatically and in real-time. The feedback reports are available to students after every class giving them opportunity to self-evaluate. The results of this study have shown that using the innovative ROFSET framework there is a visible and remarkable improvement in students' performance due to the instant, real-time feedback. It was clearly evident, based on the results of this study that students became much more active and engaged in the class.
\end{abstract}

Keywords: Education, Class Participation, Student engagement, ROFSET

\section{INTRODUCTION}

Class participation by the students is an effective learning strategy and a valuable pedagogical tool through which students are engaged to achieve the learning outcomes of the course. (Lin, 2015). Teachers assess on the basis of class participation if they are understanding and learning the concepts of the course correctly. Teachers engage the students in class participation by asking questions directed towards the class or to a particular student; the students themselves give their opinion about the topic that is under discussion or comment on the opinion given by the fellow student. (Ghalley \& Rai, 2019). However, there is always a challenge for the teachers to track measure and analyze the student's class participation in an objective and an unbiased way. Further, students also expect feedback on their class participation on a regular basis to improve upon the areas where they may be lacking. The use of internet connected technology is ideally 
suited to resolve many problems associated with tracking, measuring and analyzing student class participation. (Jessica, 2015). The following study presents the results obtained by applying ROFSET (Realtime Objective Feedback System for Effective Teaching) software for tracking, measuring and analyzing student class participation.

\section{LITERATURE REVIEW}

\subsection{Class Participation}

Learning can be defined as acquiring new or modifying existing knowledge, skills or behavior. Students need to be active in the quest for acquiring or modifying existing knowledge, behavior and skills. Various kinds of student behaviors have been observed in the class rooms ranging from sitting quietly, take notes, listening, doing something else of asking questions, giving opinion or answering the questions posed. The later three are the active types of class participation. (Abdullah, Abubakar, \& Mahbob, 2012).

Student participation is a mandatory part of active learning. For effective learning it is important that both students and teachers participate in class. Benefits of class participation are many including that the students who participate actively in class learn more than those who do not. However, students often become passive and do not participate in the class. Active students get better results and achieve greater success in learning as compare to students who are passive in class participation. (Abdullah, Abubakar, \& Mahbob, 2012). Teachers often include class participation marks in the overall assessment to encourage students to participate in the class and do back ground study to come prepared for the class. The reason for including class participation in overall assessment is that it encourages active learning and it also provides opportunities to learn from class fellows.(UNSW, 2019).

There are many aspects of student class participation. These aspects range from participating by giving opinion, making a comment, asking questions and being attentive to the proceedings in the class.(Rocca, 2010). It is wrong to narrowly define student participation as how many times have the students raised their hands. Students' participation also includes writing, researching and participation in small group activities.

It has been identified that logistics, students' traits, class room environment and the teacher play a significant role in encouraging the student for class participation. Further small class size, constructive feedback, respectful demeanor and relevance of the topic to real life situation help encourage the students to participate. (Susak, 2016). The criteria for assessing class participation include preparation, contribution to discussion, group skills, communication skills and attendance that also includes punctuality. (Dancer \& Kamvounias, 2005).

In a study conducted in Bhutanese school environment the research results show that the following factors influence the class participation: teachers, friends, class room size, preparation and language. Supportive teachers improve class participation, if class fellows are supportive and familiar they will improve class participation, small size of the class also has a positive impact on class participation as each student feels that there is a chance of participation and further prior preparation for the class also has a positive impact on the class participation and finally command over the language that is used as medium of instruction also increases the class participation. (Ghalley \& Rai, 2019).

The lecturer, teacher has a major role to play in encouraging students to participate in the class. A teacher approach towards students if encouraging and respectful then the students would be forthcoming to participate. There are inhibitions to class participation and one of them is that students do not want to feel embarrassed among the peers and in front of teacher if the fear that wrong answers would be mocked.

Both the quantity and quality of class room participation are important however greater focus has remained in the area of quantitative analysis of participation where it is recorded that how many times student has offered unsolicited and volunteered responses, these responses include asking questions, offering an opinion of comment and also questioning the peers' opinion.(Susak, 2016)

Attendance has been taken as an important factor in assessing the class participation. The students who are punctual and regular are marked higher in grading the class participation. Further, some instructors give marks solely on the attendance considering it as the proxy of class participation though many scholars have objected to this practice. (Czekanski \& Wolf, 2013).

\subsection{Assessment of Students Participation}

Student assessment has always been a challenging task for the faculty especially in case of class participation. When the class size is high, often the class sizes in higher education exceeds 100 students, it is become unmanageable to track each students class participation. Further, teachersoften give good marks 
to students scoring well in other assignments in class participation head as well. Teachers have explained that they feel that awarding marks for class participation are often at best a guess. (SPH, 2019)

Most of the methods used for class participation places an extra burden on teachers to remember the names of the students who are participating regularly hence it becomes very difficult for the teachers track objectively the students' class participation. (Armstrong \& Boud, 1983). The teachers also use logs that are filled manually and it often takes precious time away from the teachers from productive tasks and the logs do not automatically inform the students about their performance.

The assessment of class participation differs from other assessment activities as it is not separated in time or place from usual classes as the students are assessed within the same context of the class. The concern is there are the possibilities of bias and prejudice in the award of class participation marks by the teachers. (Rogers, 2013). Usually class participation grading is used as a fudge factor to arrive at a desirable grade. Therefore, many scholars have advised against grading class participation as it is considered arbitrary. (Bean \& Peterson, 1998).

\section{ANALYSIS}

To resolve the problems in tracking, measuring and analyzing class participation in an objective and unbiased way an innovative technology based app has been developed that track the quantity, quality and various other aspects of class participation in real time and gives a constant feed back to the student and instructor about the performance of student on this important learning criterion. This App is based on recently introduced quality assurance software ROFSET (Real-time Objective Feedback System for Effective Teaching).

Following are the key facets of ROFSET Framework.

a. Real-time: The data related to student learning is captured in real-time,

b. Non-intrusive: The software does not interferer or intrudes in the teaching.

c. Objective analysis: It eliminates the changes of prejudice and bias on part of the teacher as it is machine-based system thus it is not subjective.

d. Automated: Data capture and analysis of teaching and learning is done automatically hence the manual recoding of the student's learning is not required thus the system significantly reduces the workload of the teacher.

e. Artificial Intelligence (Al) engine: The embedded algorithms in the ROFSET Framework perform all the inferences on data. Al Engine generates reports and provides feedback to teachers on all Teaching and Learning Key Performance Indicators (TL-KPI).

\section{RESULTS}

One of the aspects of class participation is answering the questions placed by the instructor. The quantity of such participation is important and in a semester a student is expected to participate for a certain numbers of times. Further, quality of the answer is also a matter of high importance as it suggests the prior preparation, attention and focus in the class, ability to articulate the answer and understand the topic of discussion. Without being punctual and regular in the classes, students cannot participate regularly (quantitative aspect) and effectively (qualitative aspect). Hence, punctuality and regularity in attending the classes has a direct bearing upon the quantity and quality of class participation.

The following table (Table 1) presents the results obtained by applying ROFSET application for recording the class participation of the students. A sample of 10 students has been taken from a class and the results of class participation in four lectures have been shown.

\begin{tabular}{|r|r|r|r|r|r|r|r|r|r|r|r|r|r|r|r|r|r|r|r|}
\hline & \multicolumn{1}{|c|}{ Lecture 1 } & \multicolumn{1}{|c|}{ Lecture 2 } & \multicolumn{2}{|c|}{ Lecture 3 } & \multicolumn{2}{c|}{ Lecture 4 } & \multicolumn{5}{|c|}{ Total (4 Lectures) } \\
\hline Student ID & SP & QP & Att & SP & QP & Att & SP & QP & Att & SP & QP & Att & SP(4) & QP(1,2,3) & LAtt(220) & Att(4) \\
\hline $\mathbf{1 0 0}$ & 1 & 1 & 5.5 & 1 & 2 & 5.5 & 0 & 0 & 5.5 & 1 & 1 & 5.5 & 3 & 4 & 0 & 4 \\
\hline $\mathbf{2 0 0}$ & 0 & 0 & & 0 & 0 & & 0 & 0 & & 1 & 1 & 5.5 & 1 & 1 & 16.5 & 1 \\
\hline $\mathbf{3 0 0}$ & 1 & 1 & 5.5 & & & 5.5 & 1 & 1 & 5.5 & & & 4.7 & 2 & 2 & 0.8 & 4 \\
\hline $\mathbf{4 0 0}$ & 0 & 0 & 0 & 0 & 0 & 0 & 0 & 0 & 0 & 0 & 0 & 5.5 & 0 & 0 & 16.5 & 1 \\
\hline $\mathbf{5 0 0}$ & 1 & 1 & 5.5 & 1 & 2 & 5.5 & 0 & 0 & 5.5 & 0 & 0 & 5.5 & 2 & 3 & 0 & 4 \\
\hline $\mathbf{6 0 0}$ & 1 & 2 & 4.6 & 1 & 1 & 5.2 & 1 & 2 & 5.5 & 0 & 0 & 5.2 & 3 & 5 & 1.5 & 4 \\
\hline $\mathbf{7 0 0}$ & 0 & 0 & 0 & 1 & 3 & 5.5 & 0 & 0 & 5.5 & 1 & 2 & 4.2 & 2 & 5 & 6.8 & 3 \\
\hline $\mathbf{8 0 0}$ & 0 & 0 & 4.5 & 1 & 2 & 5 & 0 & 0 & 5 & 1 & 2 & 5.5 & 2 & 4 & 2 & 4 \\
\hline $\mathbf{9 0 0}$ & 1 & 1 & 5.5 & & & 4.1 & & & 5.5 & & & 4.7 & 1 & 1 & 2.2 & 4 \\
\hline $\mathbf{1 1 0}$ & 0 & 0 & 0 & 0 & 0 & 0 & 0 & 0 & 0 & 0 & 0 & 5.5 & 0 & 0 & 16.5 & 1 \\
\hline
\end{tabular}




\section{Table 1}

\begin{tabular}{|l|}
\hline Interpretation for Table 1 \\
\hline Pa - effort \\
\hline QP - Student academic ability \\
\hline Att - Discipline, organization, seriousness \\
\hline Key \\
\hline SP - Student Participation \\
\hline QP - Question Points \\
\hline Attendance \\
\hline LAtt - Late attendance \\
\hline
\end{tabular}

\subsection{Interpretation of the Data}

To explain the data we take Student with ID 100 as example. The student has participated in the class by answering the questions from the teacher in Lecture 1,2 and 4 , hence in total 3 lectures. The quality of the answer as assessed by the teacher ranges from 1-5 (normalized). The student has got 1, 2, 0 and 1 marks in Lecture 1,2,3,4 respectively. Hence, he has got total 4 marks in the QP part that represents student's academic ability. The student's discipline, organization and seriousness is evaluated on the basis of punctuality and regularity of attending the classes. If the student is punctual and attends the full lecture of 55 minutes he has been given 5.5 marks. As it is shown the student has attended all 4 lectures punctually without being late therefore he has got 5.5 marks in all of his lectures. His marks for late attendance are zero and for attendance he has got full marks 4 .

The complete data of the class participation is instantly available to the teacher as the students by using the application of ROFSET on their mobiles record the number of times they participate the class, by entering the marks given to them by teacher on the quality of their answers and by logging in to their devices as they enter the class (in time or late). The teacher also gets instant message if the data is recorded correctly with respect to the number of times they participate and the marks given to them about the quality of their answers.

Further, if the student is late, as it is in the case of student with ID 300 in lecture 4, he will be given less marks based on the minutes he has been late. Here, student is given 4.7 marks that suggest that he has been late for 8 minutes. In this way the ROFSET application gives a complete and accurate picture of the student's punctuality and regularity thorough out the semester.

Finally, the total picture of class participation both quantitatively and qualitatively is given and the attendance record of the student in terms of punctuality and regularity is also shown. The lesser marks in Late Attendance the better and the higher marks in attendance the better. In Figure 1 the graph represents the performance of the student (ID 100) on the Class Participation, Quality of Participation and Attendance.

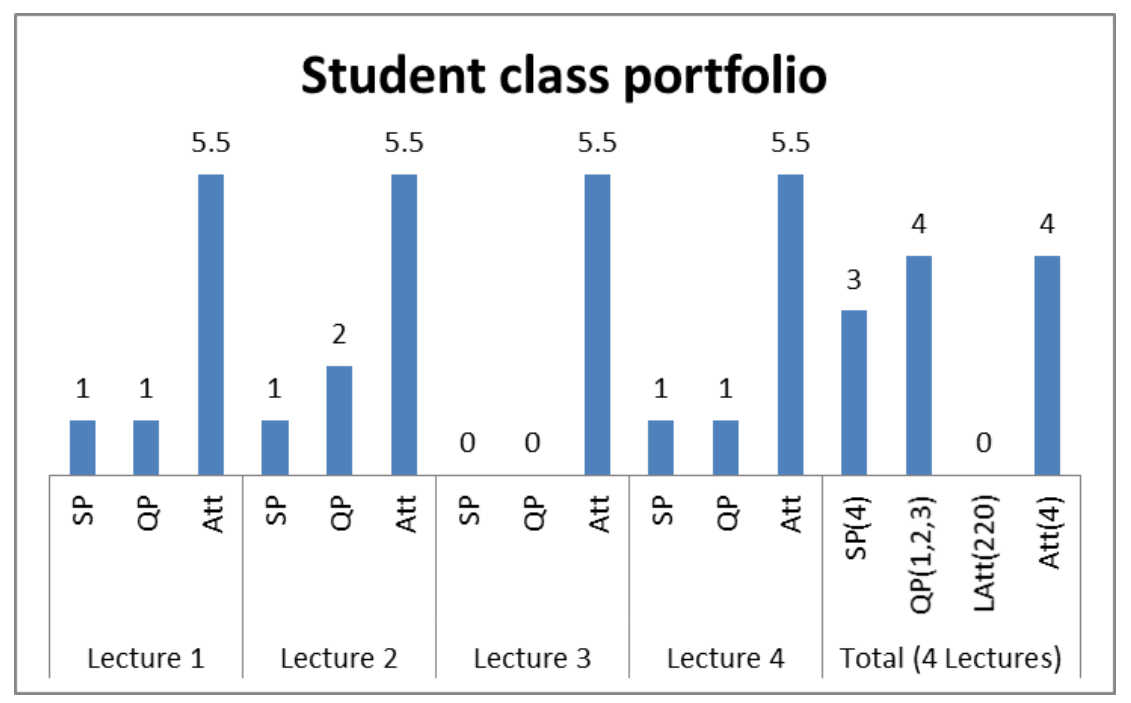

Figure 1 


\section{DISCUSSION}

Keeping the track of class participation is a challenge for a teacher with large number of students who participate multiple times in a semester. The result is that the teachers most of the time allocates the marks of class participation without objective data at hands that either enhances the grade of the student or diminishes his grade. Further, the punctuality is marked with either "Present" or "Late" without considering that by how much time a student has been late in the class therefore a student who has been late for 10 minutes and a student who has been late for 30 minutes are both given "Late" status.

Further, if the student has not been attending regular classes and is late continually it should have a bearing on his class participation marks. The above data represent one of the aspects of class participation the quantity and quality of the questions asked in conjunction with attendance (punctuality and regularity) that has been recorded through ROFSET framework. Other aspects of class participation can also be recorded such as student giving his opinion about a topic without being asked by teacher, or commenting on the answer of fellow student.

Through ROFSET framework a more robust, objective and accurate picture of class participation is emerged with student getting feedback and record of his performance in real-time.

The real-time status of the class participation by the student also enables him to get motivated to perform better if his performance is falling. The ROFSET framework application also reduces the burden on the teacher to keep the record of class participation manually or in memory (often leads to guess work about class participation as it is almost impossible to recall how many times each student had participated and how was the quality of participation).

\section{CONCLUSION}

The use of Real time, Artificial Intelligence application of ROFSET framework results in an objective, fair, efficient assessment of class participation by the student and thus enables both students and teachers to see objectively the contribution of class participation in the overall grade in justifiable manner.

\section{REFERENCE LIST}

Abdullah, M. Y., Abubakar, N. R., \& Mahbob, M. H. (2012). Student's participation in classroom: What motivates them to speak? Procedia: Social and Behavioral Sciences, 516-522.

Armstrong, M., \& Boud, D. (1983). Assessing Participation in Discussion: An Assessment of the Issues.". Studies in Higher Education , 33-44.

Bean, J. C., \& Peterson, D. (1998). Grading Classroom Participation. New Dirsctions for Teaching and Learning, 33-40.

Czekanski, K. E., \& Wolf, Z. R. (2013). Encouraging and Evaluating Class Participation. Journal of University Teaching \& Learnning Practice.

Dancer, D. M., \& Kamvounias, P. (2005). Student involvement in assessment: A project designed to assess class participation fairly and reliably. Assessment \& Evaluation in Higher Education, 30(4), 445-454.

Ghalley, L. R., \& Rai, B. M. (2019). Factors Influencing Classroom Participation: A Case Study of Bhutanese Higher Secondary Student. Asian Journal of Education and Social Studies , 1-14.

Jessica. (2015, August 8). 5 WAYS TECHNOLOGY CAN ENCOURAGE CLASS PARTICIPATION. Retrieved from THINK INCLUSIVE: https://www.thinkinclusive.us/5-ways-technology-canencourage-class-participation/

Lin, C. L. (2015). The value of class participation as an assessment tool in the English language Class Room. ELIS: Class room Inquiry.

Rocca, K. A. (2010). Student Participation in the College Classroom: An Extended Multidisciplinary Literature Review . Communication Education, 185-213.

Rogers, S. L. (2013). Calling the Question: Do College Instructors Actually Grade Particpation? College Teaching, 11-22.

SPH. (2019, December 16). Class Participation. Retrieved from BU School of Public Health: 
https://www.bu.edu/sph/faculty-staff/teaching-and-advising/educational-strategies-andtechnology/assessing-class-participation/

Susak, M. (2016). Factors that Affect Classroom Participation. Theses.

UNSW. (2019, March 4). Grading Class Participation. Retrieved from UNSW, Sydney: Teaching: https://teaching.unsw.edu.au/assessing-classroom-participation 